\title{
Em busca de uma "imagem crítica": memória, ausências e dor em A imagem que falta, de Rithy Panh
}

\author{
Marcelo Ikeda ${ }^{1}$
}

Resumo: O objetivo deste artigo é explorar a relação entre imagem, identidade e memória na obra do cineasta cambojano Rithy Panh, em especial a partir de um dos seus filmes, A imagem que falta (2013). Procuramos analisar as opções éticas e estéticas do realizador, ao buscar representar a experiência de sobreviver aos campos de trabalho forçado no regime do Khmer Vermelho, como modo de conviver com a dor e o sofrimento. O realizador Rithy Panh parte do cinema em primeira pessoa, ou seja, de suas memórias singulares, para buscar não simplesmente um método de cura, mas uma forma de prolongamento de sua experiência pessoal, visando a uma memória coletiva, em busca das ruínas ou dos vestígios no presente da identidade do povo cambojano. Seu sofrimento individual se transforma, então, em uma poética de uma dor coletiva. A partir dos conceitos de "imagem crítica" e "imagem aurática", conforme desenvolvidos por Didi-Huberman, em seu livro O que vemos, o que nos olha (2010), o artigo pretende examinar as opções do realizador,ao aproximar o espectador do que foi o massacre, ao mesmo tempo em que o mantém a certa distância, preservando-nos de nos aproximar em demasia do horror.

Palavras-chave: imagem; memória; sofrimento; documentário; Khmer Vermelho.

\begin{abstract}
The aim of this article is to explore the relationship between image, identity and memory in the work of Cambodian filmmaker Rithy Panh, especially in one of his films, The Missing Picture (2013). The article analyzes the filmmaker's ethical and aesthetic options by representing the experience of surviving the Khmer Rouge forced labor camps as a way of dealing with pain and suffering. The director Rithy Panh starts from the first person cinema, that is, from his unique memories, to seek not simply a method of healing, but a way of prolonging his personal experience aiming at a collective memory, in search of the ruins or vestiges in the present of the identity of Cambodian people. His individual suffering then becomes a poetic of collective pain. From the concepts of "critical image" and "auratic image", as developed by Didi-Huberman in his book What we see, what look at us, the article intends to examine the filmmaker's options to make the spectator aware of the effects of the massacre, but at the same time maintaining us at a distance, keeping us from getting too close to the horror.
\end{abstract}

Keywords:image; memory; suffering; documentary; Khmer Vermelho

1 Professor do Curso de Cinema e Audiovisual da Universidade Federal do Ceará (UFC). Doutorando no Programa de Pós-Graduação em Comunicação da Universidade Federal de Pernambuco (UFPE). E-mail: <marcelogilikeda@gmail.com>. 
"Talvez sobrevivamos às doenças e escapemos às seleções, talvez aguentemos o trabalho e a fome que nos consomem, mas, e depois?" (PRIMO LEVI, 1988, p.54)

\section{Introdução}

O objetivo deste artigo é explorar a relação entre imagem, identidade e memória na obra do cambojano Rithy Panh, em especial a partir de um dos seus filmes, A imagem que falta (2013). Toda a obra de Rithy Panh é baseada no espanto deste realizador, diante do processo de massacre do povo cambojano,por elementos supostamente civilizatórios. Seus filmes falam do abismo entre os sonhos singulares do ser humano e o esmagamento da liberdade, pela opressão de um regime autoritário.

Nascido no Camboja em 1964, Rithy Panh é um sobrevivente dos campos de trabalhos forçados,implementados pelo Khmer Vermelho. Em 1979, com apenas catorze anos, conseguiu migrar para a Tailândia e, de lá, para a França, onde começou a estudar cinema no prestigioso IDHEC (Institutdeshautesétudescinématographiques). Desde então, desenvolveu uma filmografia toda voltada à reflexão sobre o passado e a memória do povo cambojano, sempre em coprodução com a França, que se tornou o seu segundo país. Apesar de ter realizado longas-metragens de ficção, como Condenados à esperança - Neaksre (1994), que foi o primeiro filme cambojano a concorrer à Palma de Ouro no Festival de Cannes, ou Uma barragem contra o Pacífico (2007), estrelado por Isabelle Huppert, seu mais típico trabalho, o diretor ganhou maior notoriedade pelo documentário. Em S21 - A máquina de morte do Khmer Vermelho (2003), Panh reúne três dos únicos sete sobreviventes do centro de detenção do regime do Khmer Vermelho para contar sobre as marcas de suas experiências no centro. Entretanto, o filme não abordaapenas o relato destas vítimas, uma vez que promove o encontro de um dos sobreviventes com um dos carcereiros do centro. Os vestígios do passado se tornamvivos no presente, não apenas na geografia física do prédio, que agora se tornou um museu, mas especialmente nos corpos e gestos dos sobreviventes.

Seus filmes são, portanto, obras políticas, sobre o extermínio das populações cambojanas, sobre a necessidade de não silenciar diante do sofrimento. 
Mas o que confere destaque ao realizador, no cenário do audiovisual contemporâneo, é como seus filmes refletem sobre esse processo sociopolítico, por meio de uma complexa reflexão sobre o papel das imagens nesse processo de escavação das ruínas de um passado.

Em 1975, o Khmer Vermelho tomou o poder no Camboja, estabelecendo um regime totalitarista, que provocou a morte de milhões de cambojanos (KIERNAN, 1996). Houve o completo fechamento de fábricas e comércios, além de bancos e a extinção do regime monetário. Além disso, promoveu-se a total supressão da propriedade privada. O Camboja se tornou um "estado sem classes", em que a função de todos passaria a ser o trabalho integral em campos agrícolas de trabalho forçado. Segundo o discurso oficial do novo regime, liderado pelo ditador PolPot, seria o esforço necessário para o processo de reconstrução do país. A cidade de Phnom Penh, capital do Camboja, tornou-se um enorme deserto de prédios e residências abandonados. Na prática, representou um processo de extermínio, em que milhões morreram de fome e fadiga, pois trabalhavam em regime de escravidão, em troca de uma cuia de arroz e água.

\section{As potências e os riscos das imagens de extermínio}

Rithy Panh é uma testemunha viva desse massacre, tendo sido um dos sobreviventes dos campos de trabalho forçado. As marcas desta história permanecem em sua vida, ao testemunhar o massacre de milhares de pessoas, inclusive presenciando a morte de seu pai e de sua mãe.

Após o fim do regime, Panhse refugiou na França, encontrando no cinema uma possibilidade detranscriar a experiência dos campos não apenas como instrumento para sobreviver ao trauma, mas como um meio de reflexão para o mundo, em relação à importância do resgate da memória do extermínio, conferindo visibilidade a uma outra história do povo cambojano.

Nesse sentido, a obra de Panhse insereem uma linhagem do documentário contemporâneo, em torno das “escritas de si” (KLINGER, 2012), em que a própria experiência subjetiva do realizador se torna motor para um processo de inscrição de imagens. Este processo afasta o documentário contemporâneo da 
vertente consolidada no documentário clássico, em que a objetividade ou a informação se cristalizam como forma de dar a ver um mundo, em que o conhecimento se revela como pilar de uma relação estável com o seu objeto.

Ao mesmo tempo, o "pacto autobiográfico", na expressão de Philippe Lejeune (2008), é um recurso utilizado por Panh para promover uma reflexão sobre o destino de uma nação, extrapolando a sua motivação meramente individual. Esta inclinação coletiva afasta a escrita de si de Panh dos típicos riscos dos domínios das novas tecnologias da informação, em que a exposição pessoal muitas vezes se torna função de mercadoria, em uma sociedade do espetáculo regida pela superexposição da intimidade, como um verdadeiro "show do eu" (SIBILIA, 2008)

Em particular em A imagem que falta, Panh parte do cinema em primeira pessoa, ou seja, de suas memórias singulares, para buscar não simplesmente um método de cura, mas uma forma de prolongamento de sua experiência pessoal, visando a uma memória coletiva, em busca das ruínas ou dos vestígios no presente da identidade do povo cambojano. Seu sofrimento individual se transforma, então, em uma poética de uma dor coletiva.

Como diz Anita Leandro (2014, p.4), "Na obra de Rithy Panh, a escrita da história na primeira pessoa não remete a uma subjetividade ou a uma voz que diz 'eu', mas ao testemunho do outro - as vítimas, os mortos e seus algozes, que testemunham diante do cineasta."

Diante disso, o que foram os campos? Como retratar, por meio das imagens (dos elementos da linguagem audiovisual), a dor de sobreviver a uma experiência tão traumática? Seria possível para o cinema apresentar o que de fato foi? Ou, ainda, seria possível ativar, no espectador, um estado sensível que o faça compartilhar uma experiência?

Em Hiroshima monamour (1959), Alain Resnais trata de questões semelhantes, ao mostrar uma paixão entre um japonês sobrevivente do bombardeio nuclearde Hiroshima e uma atriz francesa. Ela diz a ele que compreende a sua dor. Ele retruca que "ela não viu nada". Ela diz que sabe o que aconteceu, pois viu um conjunto de documentos, textos e notícias de jornal sobre os efeitos da bomba atômica na população japonesa - e enquanto ela narra, o filme apresenta 
a nós, espectadores, por meio de fotos e imagens de arquivo, documentos que registram o massacre. Ainda assim, por sobre as imagens, ouvimo-lo dizer, repetidamente, "você não viu nada". Nessa passagem, de forma sutil, Resnais sugere que o conhecimento não substitui a experiência. Por mais que tenhamos acesso aos registros, como fontes históricas, não somos sobreviventes do massacre, não temos inscrita, em nossos corpos e em nossa memória, a experiência traumática do sofrimento (OLIVEIRA, 2010). O que seria, portanto, ver? Como representar a dor? O que a imagem de fato pode para aquele que não teve a experiência direta do acontecimento? Devemos, então, abandonar o foco do campo da representação direta para avançar para a esfera da experiência, ligada mais diretamente à estética? Mas como estetizar uma experiência, sem que o processo de transcriação abandone a sua dimensão histórica e o seu compromisso ético com o respeito à dor?

Sontag (2003) alerta sobre os riscos de desvirtuamento dessa empreitada. Para alertar ao público da dimensão da tragédia, o fotógrafo (o diretor, enfim, o produtor de imagens) pode, por variados motivos, optar por gerar o choque. As imagens podem acabar por embelezar ou objetificar os acontecimentos, gerando uma espécie de sensacionalismo ou espetacularização da barbárie.

Como exemplo, é possível citar estratégia utilizada por Steven Spielberg em O Resgate do Soldado Ryan (1998). Para retratar o desafio de reproduzir a experiência do desembarque das tropas aliadas na Normandia, na Segunda Guerra Mundial, a célere cena da "praia de Omaha" produz um enorme impacto no espectador, em função do realismo cru das imagens. O realizador não estava lá (não é um sobrevivente, comoPanh), mas se baseou em ampla pesquisa histórica para reconstituir a experiência da guerra. A estratégia (palavra que condiz com o discurso utilizado, de influência bélica) de Spielberg é a da reconstituição literal. No entanto, os efeitos do cinema contemporâneo fazem com que a cena assuma um tom de espetacularização, em um tom que não se diferencia muito do discurso publicitário. Temos um plano ponto de vista, quase como um game como Doom, em que o protagonista mata a tiros os vilões. Paradoxalmente, as imagens desenvolvem, no espectador, uma espécie de prazer (CAVICHIOLLI e REIS, 2008). O som dolby estéreo 5.1 e as imagens hiper-realistas provocam, no espectador, um 
estado físico de imersão sensorial, como uma sensação de montanha russa (ou seria de roleta russa?). O que dizer, então, dos filmes atuais produzidos em $3 \mathrm{D}$ pelas majors, em escala global, que utilizam as mais sofisticadas invenções tecnológicas para estimular a espetacularização da dor?

Este estado induz a um sentimento imersivo, ligado a uma hiperexcitação dos estímulos sensoriais, em vez de incitar o espectador a refletir acerca do momento histórico e da angústia diante da dor. Sontag (op. cit.), mesmo sem citar o filme de Spielberg, aponta que a sucessiva exposição do público a estratégias extremadas de choque pode produzir, no espectador, um efeito cada vez mais reduzido. Tal fenômeno ocorre, uma vez que ele se habitua à multiplicação das imagens de choque, acostumando-se ao horror das imagens, contexto que provoca uma anestesia dos seus sentidos e a neutralização de seu impacto. Assim, em um mundo saturado de informações, as imagens da barbárie nos revelam, de fato, o que é o conflito, ou acabam nos anestesiando, tornando-nos ainda mais insensíveis? As imagens nos revelam o horror da guerra e da morte, ou acabam provocando o seu oposto: a sustentação dos motivos da indústria bélica?

Rithy Panh está muito mais próximo de Resnais do que de Spielberg, pois o seu interesse se concentra não estritamente em descrever o que de fato foi, mas em despertar a reflexão sobre as ruínas do massacre promovido pelo Khmer Vermelho no Camboja atual. Ou ainda, tal obra procura sensibilizar o espectador, sem empurrá-lo para o contato com uma experiência de choque. Mas como representar a dor? Se Sontag aponta a dificuldade de lidar "com a dor do outro", Panh prolonga esta ideia, ao refletir se é possível sensibilizar o outro sobre o seu próprio sofrimento. Além disso, também considera como é possível fazê-lo, a partir das imagens.

A tarefa de Panhse aproxima dos impasses encontrados pelos autores da chamada "literatura do testemunho" (SILVA, 2003). Diante do caráter fragmentário da memória e da incompletude do relato, o testemunho é sempre marcado por uma falta, por uma certa escritura no abismo. Nesse sentido, inscreve-se uma espécie de fenda, que marca um distanciamento entre o estado interior do sobrevivente com o mundo exterior, ou ainda, entre o passado e o presente. $\mathrm{O}$ narrador de si retoma a vida por meio desta narrativa, que faz com que as me- 
mórias ressurjam diante do silêncio e das destruições impostas pelo real vivido. A linguagem trafega entre a necessidade de lembrar o que houve e o desejo de esquecer a humilhação e o sofrimento, entre o desejo de potência de exprimir e a mesma dificuldade de transformar em signos um esvaziamento interior. Toda a obra de um autor, como Primo Levi, é marcada por esta fissura: ele é, para sempre, “um homem de Auschwitz”, mesmo após ter saído de lá. Sua literatura é uma tentativa de sobreviver ao trauma, sucumbindo pela falta de aparente sentido em prosseguir vivendo. É doloroso reconhecermos que a arte não foi suficiente para salvá-lo. "Talvez sobrevivamos às doenças e escapemos às seleções, talvez aguentemos o trabalho e a fome que nos consomem, mas, e depois? ”(LEVI, 1988, p.54)

\section{As opções éticas e estéticas de Rithy Panh: em busca de uma "ima- gem crítica"}

Na pesquisa para $A$ imagem que falta, Panh se deparou com uma dificuldade adicional, que acabou por condicionar o seu processo de realização posterior. Em um imenso trabalho de imersão em acervos e arquivos, Panh buscava as imagens-sobreviventes produzidas nos campos de trabalho forçado. No entanto, elas não existem. Durante o processo, Panh encontrou apenas imagens produzidas pelo próprio regime. O Khmer Vermelho possuía uma equipe de cinegrafistas que filmavam os campos, exibindo os feitos do regime de Pol Pot, na busca da reedificação de um projeto de desenvolvimento do Camboja. Aparentemente documentais, as imagens são, de fato, meros filmes de fiç̧ão. Nos termos de Panh, são "filmes ruins", que deixam evidente a falsidade de suas intenções. Pol Pot é, portanto, não apenas um ditador, uma vez que também se revela como um diretor (um metteurenscène), que monta artificialmente uma espécie de palco de teatro para servir aos fins do seu regime ditatorial. As imagens que sobreviveram, portanto, exibem o ponto de vista oficial do regime. Elas não mostram $o$ que de fato foi, ou ainda, não correspondem às memórias dos sobreviventes do massacre. Trata-se da história oficial, narrada pelos opressores. As imagens mostram uma mentira, um laboratório-teatro manipulado por um monstro. Com isso, aponta-se para o fato de que as imagens podem ser um testemunho histórico ilusório. Aponta-se para uma crise da representação. 
Para buscar uma outra experiência dos campos de trabalho forçado, do ponto de vista dos oprimidos, é necessário, portanto, ir além das imagens, é preciso buscar o que as imagens intencionalmente escondem do espectador, ou aquilo que não pode ser encenado. Dessa forma, é fundamental ir além dos documentos históricos que existem. Panhse coloca na missão de encontrar essa imagem que não existe. Como, então, apresentar para o espectador essa informação que falta, que perdura simplesmente na memória do realizador? Ou ainda, como traduzir, por meio de cenas, a experiência da dor?

Panh está, portanto, diante de um impasse: busca o dever moral de representar aquilo que não apenas não pode,mas que também não deve ser representado. Como fazê-lo?

Se as imagens que mostram o massacre não existem (não puderam ser criadas), ou não sobreviveram (não puderam ser encontradas), Panh conclui que se torna preciso, então, criar imagens que reproduzam esse imaginário.

Panh opta por reconstituir as imagens dos campos não tanto com documentos, fotos ou imagens, mas principalmente por meio da construção de uma espécie de maquete, com bonecos de madeira e estrutura de argila. Uma narração - em primeira pessoa - descreve o cotidiano dos campos, a partir das imagens que mostram a disposição da arquitetura dos espaços e a presença dos corpos (os bonecos de argila). Se, desde os escritos de André Bazin (1991), o realismo no cinema está frequentemente associado à chamada "ontologia da imagem fotográfica”, nesse caso, o real está além da imagem, já que ela falta. Para criar as cenas dos campos, Panh opta pela recusa em descrever visualmente, de forma direta, os mecanismos de aniquilação. Em $A$ imagem que falta, não há sangue; não há mutilação dos corpos. Como contraponto ao horror da morte e às estratégias de hiperexcitação, por meio da espetacularização das imagens, Panh utiliza a madeira e a argila,como uma forma de sugerir, ao espectador, a dor do massacre. A confecção dos bonecos e dos cenários revela um lado lúdico e poético, transformando os campos em um palco teatral, mas, dessa vez, completamente diferente do tosco realismo das falsas imagens produzidas pelo "diretor" Pol Pot.

Os campos de trabalho se tornam um teatro de bonecos, como se fossem um brinquedo. A palavra "brinquedo" faz referência não apenas à forma de 
rememorar a experiência do próprio diretor-sobrevivente, recuperando uma espécie de infância perdida, mas também ao papel libertário que o brinquedo tem para a criança, conforme evocado por Walter Benjamin (2002), especialmente quando a sua fabricação é artesanal. Nesse sentido, é oportuno examinar que "os brinquedos de Panh" não foram fabricados industrialmente, como produtos seriais de massa. Nem mesmo a partir de materiais processados industrialmente, como o ferro ou o plástico. A reconstrução de Panh tampouco utilizou imagens animadas - como, por exemplo, no filme Valsa para Bashir (2008) -, produzidas por programas de computador ou mesmo por desenhos. Os bonecos e os cenários construídos pela equipe de Panh foram todos construídos artesanalmente, a partir da madeira e argila. Foram feitos a mão, coletivamente herdeiras das mesmas mãos que araram a terra nos campos do regime de Pol Pot. Dada que a equipe de arte é majoritariamente cambojana, é possível dizer que, se não foram as mesmas mãos, foram as mãos de parentes e herdeiros diretos do massacre. Se Spielberg torna a experiência dos campos de batalha uma brincadeira sensorial, como um game, dialogando com a hiperexcitação da experiência imersiva do gênero de guerra dos jogos virtuais, a ousadia do gesto de Rithy Panh é deslocar o olhar do espectador do realismo cru dos registros documentais diretos para outra forma de experienciar esteticamente o acontecimento. $\mathrm{O}$ tom artesanal dos brinquedos fornece concretude ao processo de reconstituição, mas, ao mesmo tempo, aponta para uma fenda, um abismo entre a barbárie do passado e o presente, que ressignifica o acontecimento, por meio de um gesto criativo. Portanto, o uso do brinquedo não se relaciona estritamente aos termos de uma "pedagogia do trauma", mas pode ser entendido como gesto estético, que instaura a possibilidade de permanecer criando e sonhando, mesmo após ter sobrevivido à experiência do massacre. Estas imagens nos aproximam do que foi o massacre, mas, ao mesmo tempo, nos preservam de nos aproximar em demasia do horror, mantendo-nos a certa distância.

Em O que nos vemos o que nos olha, Didi-Huberman retoma os escritos de Walter Benjamin para a importância de outra dimensão do sublime, que retire seu valor supostamente religioso, como um signo da transcendência. Ou ainda, Didi-Huberman aborda uma imagem aurática, esculpida a partir de uma dialética da imanência, uma vez que está próxima e distante, ao mesmo tempo. 
Próxima e distante ao mesmo tempo, mas distante em sua proximidade mesma: o objeto aurático supõe uma forma de varredura ou de ir e vir incessante, uma forma de heurística na qual as distâncias - as distâncias contraditórias - se experimentariam umas às outras, dialeticamente (DIDI-HUBERMAN, 2010, p.148).

Essa imagem aurática estaria absorvida pela perda e pela relação íntima com a memória, rompendo a tradição de um tempo homogêneo e linear, mas incorporando o tempo como pensamento. As imagens estariam "sob nossos olhos e fora de nossa visão". Trata-se de algo que nos olha justamente a partir de sua distância; algo que nos olha, mas que, ao mesmo tempo, nos escapa. Essa imagem nos toca (nos olha) a partir de suas ausências.

Panh produz, então, "imagens críticas", conforme a expressão de Didi-Huberman. São imagens que, para além de representar objetivamente o que foram os campos de concentração, produzem um impacto reflexivo no espectador, a partir da sua ausência, ou ainda, problematizam o seu próprio status como imagens. Dessa forma, elas questionam a nossa própria maneira de vê-las, ao por em crise a própria produção de imagens.

\section{A exumação dos corpos e o sabor das frutas}

Em um determinado momento dos campos de trabalho forçado, Panh passou a ter como ofício enterrar os corpos mortos saídos dos hospitais, muitos dos quais vitimados pela fome ou sede. Panh viu os corpos mortos e tinha o dever de enterrá-los. Como representar essa imagem?

Há muitas coisas que um homem não deveria ver ou saber.

E se ele as viu, seria melhor para ele morrer.

Mas, se um de nós vê ou conhece essas coisas.

Então, ele deve viver para contá-las.

Todas as manhãs, eu costumava trabalhar no poço.

Minha pá esbarrou em ossos e crânios.

A Terra nunca é suficiente.

Eu sou aquele que será morto ou que já está liquidado.

É claro que não encontrei a imagem que falta.

Eu a procurei em vão.

Um filme político tem que descobrir o que o motivou.

Então, eu criei esta imagem, eu a vi, eu a senti.

$\mathrm{Eu}$ a segurei em minhas mãos como as pessoas fazem com um rosto [amado. 
A imagem que falta agora eu dou a vocês.

Para que não parem de olhar para nós. (A IMAGEM..., 2013).

Com este epílogo, Panh reflete, portanto, sobre o próprio estatuto da imagem. Mais do que encontrar uma imagem em si, o que verdadeiramente importa é desenvolver uma relação entre ele, que olha, e a imagem a ser olhada (a memória do realizador), ou ainda, em uma outra relação, que se revela ser o motivo para realizar o filme, entre o espectador e essas imagens. Mais do que encontrar uma imagem que objetifique o horror, o propósito de Panh é estimular uma relação do espectador distante (aquele que olha) com a experiência da guerra, a partir dessa mesma distância, sem ter que necessariamente experienciar a dor da morte, sem precisar vê-la como uma imagem.

A operação que Panh faz ao final do filme é como desenterrar os mortos, sendo possível traçar uma relação, a partir de Didi-Huberman (op.cit.), com a memória. Ao falar de uma imagem dialética, o autor cita que "a memória não é simplesmente uma coleção de coisas passadas, mas uma escavação arqueológica, como a operação de exumar o corpo de um lugar" (DIDI-HUBERMAN, op. cit., p.174). Quando uma imagem é mostrada, uma floresta de símbolos é evocada: com ela, todos os vestígios de sua história reaparecem (as árvores partidas, as tempestades). Para desenterrar, é preciso revolver a terra, escavar, tirá-la do lugar em que se acomodou.

As ruínas dos antigos campos de trabalho forçado ainda permanecem visíveis nos arredores da cidade. O tempo, ou a vergonha, cobriu a superfície do cemitério de corpos com outros afazeres aparentemente banais. Hoje, estão soterrados, seja na memória coletiva de um país que quer esquecer os tempos sombrios, seja na própria geografia física da cidade. Tornaram-se um campo de milho ou mesmo um lago artificial, cujo cheiro da água é tão estranho que ninguém ousa banhar-se nele. O que Rithy Panh promove é a escavação (uma exumação) deste passado - presente enquanto memória. É preciso ver o que há por baixo dos campos de milho e do lago artificial criados para ocultar os corpos.

Assim, o pensamento dialético não procurará simplesmente reproduzir o passado, como mera exposição de eventos que se sucederam no tempo cronológico, ou mesmo representá-lo, por meio de uma imagem-documento que 
reapresente a violência dos fatos, mas sim escavá-lo, provocar uma fenda. A imagem não reproduz um passado que lá está, mas também o produz. Como afirma Didi-Huberman (op. cit., p.177), "a imagem dialética é uma interpenetração crítica entre passado e presente, como um sintoma da memória”.

Sinto que assim, de forma muito sugestiva, o filme se inicie e termine com uma imagem de mar. É uma das raras imagens do filme em que é produzida uma sensação de experiência de imersão, e não de distanciamento crítico. O mar é algo íntimo, sensorial, vivo. Por outro lado, é uma onda feroz, forte, em que podemos nos afogar. O mar é eterno fluxo, ao mesmo tempo, devir. Sinto que o mar é essa imagem do presente e da memória que se reatualiza como processo de vida, mas eterno perigo. As imagens falam das chagas no corpo do realizador, mas ainda assim é preciso abrir os poros e respirar a experiência da vida.

Talvez por isso, entremeados com os relatos da dor e do extermínio nos campos, Panh traga também a memória de momentos felizes ao lado dos pais, antes do Khmer Vermelho assumir o poder.

\begin{abstract}
Eu me lembro dos velhos tempos em Phnom Penh, as grandes festas em nossa casa. Lembro-me de risos e música. Havia cheiro de caramelo, de peixes, de especiarias, de manga. Costumávamos dançar, a falar sem parar com nossos tios e tias. Meus primos costumavam trazer frutas. Goiaba, jaca. Neste momento, estudávamos, líamos livros. Nas noites, eu gostava de ouvir o meu pai recitando poesia. Lembro-me especialmente da doçura das coisas. (A IMAGEM..., 2013).
\end{abstract}

Qual é a experiência da dor? Como lidar com a dor do outro? Qual é o papel da imagem diante da dor? A sutileza de A imagem que falta é dar visibilidade ao massacre do povo cambojano. Entretanto, ao mesmo tempo, aponta para algo que o renova: a possibilidade de sobreviver ao massacre mantendo-se são, mantendo-se humano. É possível, ainda, criar e viver. É possível criar bonecos de argila.

É preciso se lembrar não apenas da morte, mas também da vida. É preciso não apenas falar do massacre, mas da possibilidade de sobreviver a ele. Sem negar as marcas do trauma, mas apontar para a experiência da vida, para o que permanece. Como já havia mostrado Alain Resnais em Noite e nevoeiro (1955), após a guerra, a grama dos campos volta a crescer verde. As frutas voltam a cair dos pés das árvores, elas permanecem suculentas. É preciso voltar a saboreá-las. 


\section{Referências}

A IMAGEM que falta / L'image manquante. Direção Rithy Panh. França/Camboja. 2013. $92 \mathrm{~min}$.

BAZIN, André. O que é o cinema? São Paulo: Brasiliense, 1991.

BENJAMIN, Walter. Reflexões sobre o brinquedo, a criança e a educação. São Paulo, Ed. 34, 2002.

CAVICHIOLLI, Renato Fernando; REIS, Leôncio. Jogos eletrônicos e a busca da excitação. Movimento, v.14, n. 3, p. 163-183, 2008. Disponível em: <http://seer. ufrgs.br/index.php/Movimento/article/view/2225>. Acesso em: 29 jul. 2018.

CONDENADOS à Esperança / Neak sre. Direção Rithy Panh. França/Camboja. 1994.125 min.

DIDI HUBERMAN, Georges. Cuando las imágenes toman posición. Madrid: Antonio Machado Libros, 2008. . O que vemos, o que nos olha. São Paulo: Editora 34, 2010.

HIROSHIMA, meu amor / Hiroshima,mon amour. Direção Alain Resnais. França. 1959.86 min.

KIERNAN, Ben; BOUA, Chanthou. The Pol Pot Regime: Race, Power and Genocide in Cambodia under the Khmer Rouge, 1975-1979. New Haven: Yale University Press, 1996.

KLINGER, Diana. Escritas de si, escritas do outro: o retorno do autor e a virada etnográfica. Rio de Janeiro: 7Letras, 2012.

LEANDRO, Anita. A história na primeira pessoa: em torno do método de Rithy Panh. In: Anais. XXIII Encontro Anual da Compós, Universidade Federal do Pará, 27 a 30 de maio de 2014. Disponível em: <http://compos.org.br/encontro2014/anais/Docs/GT11 ESTUDOS DE CINEMA FOTOGRAFIA E AUDIOVISUAL/anita leandro compos 2014 2222.pdf >. Acesso em: 29 jul. 2018.

LEJEUNE, Philippe. Pacto autobiográfico: de Rousseau a internet. Belo Horizonte: UFMG, 2008.

LEVI, Primo. É isto um homem? Rio de Janeiro: Editora Rocco, 1988.

NOITE e nevoeiro / Nuit et bruillard. Direção Alain Resnais. França. 1955. 32 min.

O RESGATE do Soldado Ryan / Saving Private Ryan. Direção Steven Spielberg. Estados Unidos. 1998. 169 min.

OLIVEIRA, Eduardo. Uma paisagem, um acontecimento, um poema: a poeira como uma forma de pensar o mundo. Devires, v. 7, n. 2, p. 118-131, 2010. Disponível em: <http://www.fafich.ufmg.br/devires/index.php/Devires/article/viewFile/319/180 >. Acesso em: 29 jul. 2018. 
S21: A Máquina de Morte do Khmer Vermelho / S-21, la machine de mort Khmère rouge. Direção Rithy Panh. França/Camboja. 2003. 101 min.

SIBILIA, Paula. O show do eu: a intimidade como espetáculo. Rio de Janeiro: Nova Fronteira, 2008.

SILVA, Marcio Seligmann. História, memória, literatura: o testemunho na era das catástrofes. Campinas, SP: Editora da Unicamp, 2003.

SONTAG, Susan. Diante da dor dos outros. São Paulo: Companhia das Letras, 2003.

UMA BARRAGEM contra o pacífico / Un barrage contre le Pacifique. Direção Rithy Panh. França/Camboja. 2008. $115 \mathrm{~min}$.

VALSA para Bashir / Vals im Bashir. Israel/França/Alemanha. Direção Ari Folman. 2008. $90 \mathrm{~min}$. 